\title{
Global rates of soil production independent of soil depth
}

\author{
Authors: Emma J. Harrison ${ }^{1,2^{*}}$, Jane K. Willenbring ${ }^{1,2}$, Gilles Y. Brocard ${ }^{3}$
}

\author{
Affiliations: \\ ${ }^{1}$ Scripps Institution of Oceanography, University of California San Diego, La Jolla, CA, USA \\ ${ }^{2}$ Now at Geological Sciences, Stanford University, Stanford, CA, USA \\ ${ }^{3}$ Archéorient, UMR 5133, Maison de l'Orient et de la Mediterranée, University of Lyon 2, \\ France. \\ *corresponding author email : ejharris@ucsd.edu
}

\section{ABSTRACT}

Accelerated rates of soil erosion threaten the stability of ecosystems ${ }^{1}$, nutrient cycles $^{2}$, and global food supplies ${ }^{3}$ if the processes that produce soil cannot keep pace. Over millennial timescales, the rate of soil production is thought to keep pace with the rate of surface erosion through negative feedbacks between soil thickness and the rate at which soil is produced from the underlying mineral substrate ${ }^{4,5}$. This paradigm in the Earth Sciences holds that some underlying mechanism lowers the rate of soil production when soil is thick and increases the rate of soil production when soils are thin. This dynamic balance lends support to two observations: First, soil covers $>90 \%$ of Earth's ice-free surface (NRCS) despite global erosion rates that vary by three orders of magnitude ${ }^{3}$ and second, the thickness of soils on Earth exists within a relatively narrow range even in old and deeply weathered landscapes ${ }^{7}$. However, the actual coupling mechanism between soil thickness and depth is unknown, and the functional form of the relationship is debated. Here, we question whether this balance exists and whether the apparent negative feedback instead arises from a computational artefact of how soil production rates are calculated in landscapes with changing erosion rates. As evidence, we compared sites that have likely experienced constant erosion rates and climate over geologic timescales with sites that may experience transient erosion responses to environmental change in a global compilation of 
soil production versus soil thickness. We conclude that soil production resists self-arresting behaviour in some locations and is uniformly slow in arid and semi-arid settings independent of soil depth. This result has drastic consequences for soil sustainability in the context of anthropogenically accelerated soil erosion such that an acceleration in modern erosion may not give rise to a concomitant, matched rise in soil production.

\section{MAIN TEXT}

The coupling between the depth of the soil mantle and the rate of soil production was first suggested by Gilbert in 1877 and was used in models of landscape evolution years later ${ }^{8}$. Under this conceptual framework, soil production is a self-arresting process where rates are enhanced as bedrock comes closer to the surface and dampened as soil cover thickens. Here and in the references therein, "soil" is considered physically-disturbed regolith". Powerful empirical evidence and a new geochemical methodology for measuring soil production rates was introduced by Heimsath el al. ${ }^{5}$ whose results apparently confirmed the earlier hypothesis that soil production rates depend on soil thickness exponentially. The exponential form of this relationship, popularly named the soil production function ${ }^{5}$, is frequently used to generate quantitative models of landscape evolution and soil formation and transport as well as fluxes of chemical weathering products. The soil production function contains two important theoretical predictions: self-arresting behavior that causes soil production to effectively cease at a terminal soil thickness, and the existence of a maximum soil production rate governed by local climatic and lithologic conditions. Erosion rates exceeding the maximum soil production rate result in increasing bedrock exposure ${ }^{4}$ and diminished holding capacity for nutrients, carbon, and water across landscapes. 

represent the spectrum of topographies, climates, and ecosystems on Earth. This global dataset contains a population of study areas where the data appears to support an exponential soil production function (Fig. 1A $)^{5,10-16}$ and another population of sites where it does not (Fig. 1B) ${ }^{16-}$

a

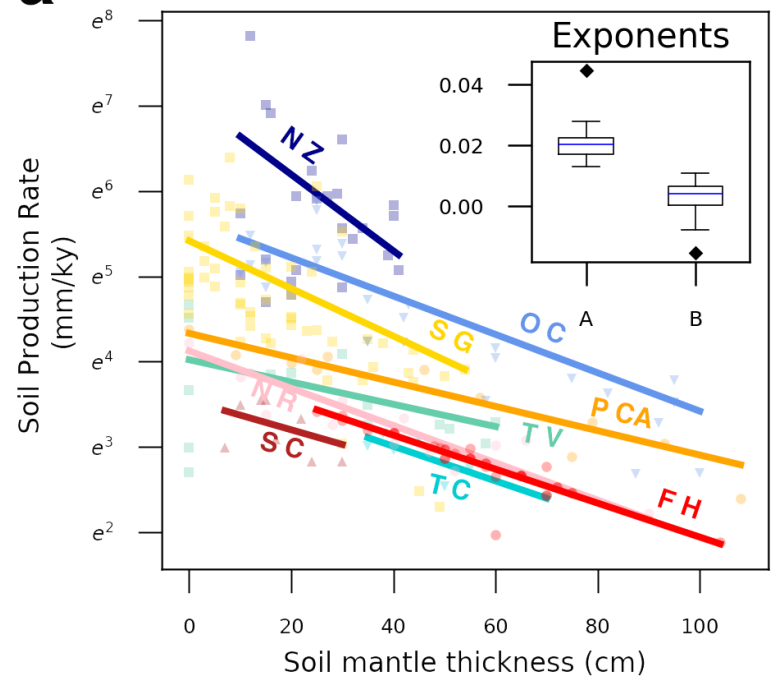

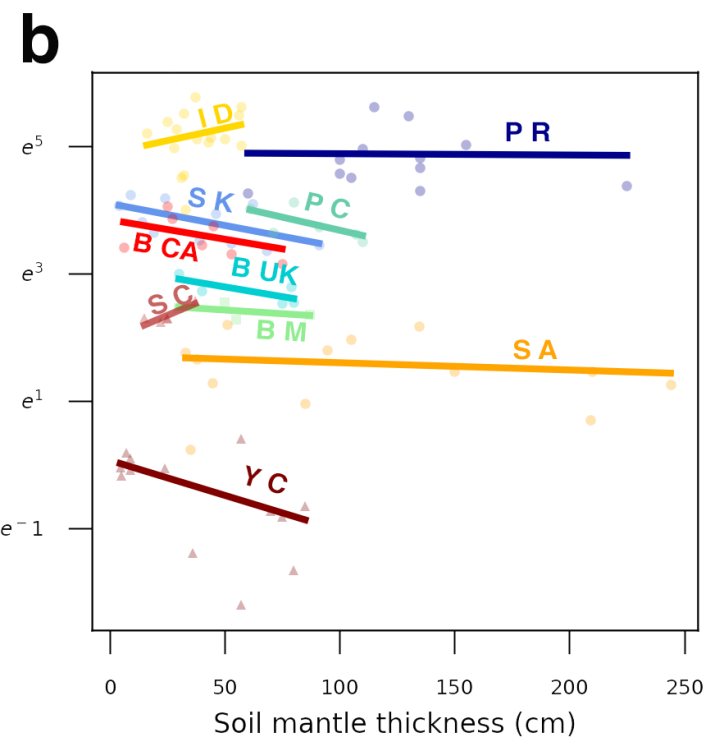

Fig. 1 - Compilation of soil production rate vs. soil depth from published literature showing empirical support for two conflicting models of depth-dependence in soil production rate data.

Markers indicate point measurement data and have shapes corresponding to the dominant lithology in the study area. Circles are granite/diorite lithologies, upside-down triangles represent sandstone, triangles are mixed plutonic and volcanic rocks, and squares represents greywacke/schists. The colours grade from dark reds to blues to represent relative differences in average annual precipitation between the sites. Fitted lines represent the best exponential fit to the dataset found with least squares regression. The exponent values for the fit lines in panels $\mathbf{a}$ and $\mathbf{b}$ are presented in the box plot inset in a. Study areas in $\mathbf{A}$ are as follows, NZ: Southern Alps, New Zealand ${ }^{15}$; OC: Oregon Coast Range, Coos Bay OR ${ }^{13}$; S G: San Gabriel Mountains, CA ${ }^{12}$; P CA: Point Reyes, CA ${ }^{14}$; TV : Tennessee Valley, CA ${ }^{5}$; N R: Nunnock River, Bega Valley, Australia ${ }^{10}$; FH: Frogs Hollow, Australia; TC: Tin Camp Creek, Australia ${ }^{11}$; S C: La Serena, Chile ${ }^{16}$. Study areas in b are as follows, ID: Salmon River Mountains, ID ${ }^{20}$; PR: Luquillo Mountains, Puerto Rico (this study); PC: 
Providence Creek, Sierra Nevada, $\mathrm{CA}^{21}$; SK: Daegwanryeong Plateau, South Korea ${ }^{19}$; B CA: Blasingame, Sierra Nevada, $\mathrm{CA}^{21}$; B UK: Bodmin Moor, UK ${ }^{18}$; SC: La Serena, Chile ${ }^{16}$; BM: Blue Mountains, Australia ${ }^{22}$; SA: Kruger National Park, South Africa ${ }^{17}$; YC: Yungay, Chile ${ }^{16}$. Map in Fig. S2.

We questioned whether a controlling variable could explain the different behaviors exhibited by the exponential-function population and the mean-centered population. The two groups cannot be differentiated by Jenny's soil forming factors ${ }^{23}$, seasonal extremes ${ }^{24}$, plant decomposition, dust deposition rates, water table heights, hillslope gradients or the depth of chemical weathering (Supplemental Information). All the study areas are upland, erosional landscapes, indicating that the mean-centered data does not show soil continually thickening beneath a non-eroding surface. Both groups include studies utilizing catena-transect sampling; therefore, the difference is not related to the slope effect of integrated sediment flux thickening the soil mantle. The only clear differentiating factor that emerges is in the presence (or absence) of dynamic equilibrium between hillslope erosion and baselevel lowering rates. The sites in the exponential-function population (Fig. 1A) all demonstrate active connections to an incising local baselevel through topographic form ${ }^{25,26}$ and at most of these sites catchment-averaged erosion rates exceed at-a-point erosion measurements (Supplemental Information). Sites in the meancentered group (Fig. 1B), on the other hand, are all geomorphically "stable" with respect to the local baselevel. This includes plateau surfaces ${ }^{19,22}$ and alpine flats ${ }^{20,27}$, relict portions of adjusting topography ${ }^{21}$, low-gradient parabolic hills ${ }^{18}$, and post-orogenic, climatically stable landscapes $^{16,17}$.

How would this factor produce the shifted dynamic between soil production and soil depth that we observe in the global data? We look to the existing conceptual models of how landscape evolution, driven by changes in climate or tectonics, impacts the thickness and distribution of soil covering in a landscape. Tectonic uplift - or baselevel fall - triggers waves of 
erosion that travel progressively upstream through river networks and upslope from the channel banks to the ridgetops ${ }^{28,29}$. The response time in soil production rate to a perturbation in surficial erosion is not empirically constrained, and it is conventional is to assume that lowering rates at the soil-saprolite and subaerial soil interfaces are linked, even if surficial erosion is unstable ${ }^{12,30}$ (Fig. 1A). We investigate the implications of an alternative conceptual model, that the timescale of equilibration to incision is shorter at the surface than at the soil-saprolite interface ${ }^{31}$ such that soil production processes respond slowly or are delayed relative to increased surface erosion. Unsteady soil thickness caused by erosive processes that strip away surficial sediment, such as land sliding, dry raveling, slumping, or gullying, violates a key assumption of the cosmogenic ${ }^{10} \mathrm{Be}$ method popularly used to determine soil production rates $^{5}$ (Fig. 2A).

Soil production rates are measured by collecting a sample of undisplaced material below the base of the soil mantle and measuring the concentration of the cosmogenic radionuclide ${ }^{10} \mathrm{Be}$ it contains $5,32,33 .{ }^{10} \mathrm{Be}$ is produced within the mineral lattice of quartz at a rate that is a function of that sample's position on Earth and its depth below the surface ${ }^{34}$. Mass removed from above the sample by chemical and physical erosion increases the ${ }^{10} \mathrm{Be}$ production rate because the energy catalyzing the spallation reaction is attenuated as it passes through Earth materials. The ${ }^{10} \mathrm{Be}$ production rate for any sample is an exponential function depending on the bulk density of the overburden and the sampling depth. Therefore, for these measurements to be accurate, the sample depth must have remained constant over the time period of ${ }^{10} \mathrm{Be}$ accumulation ${ }^{5}$. If these boundary lowering rates are temporarily out of sync the apparent depth to saprolite will suggest a higher rate of ${ }^{10} \mathrm{Be}$ production $\left(P_{z}\right.$ in Fig. $\left.2 \mathrm{~B}\right)$, and consequently, a faster soil production rate. 

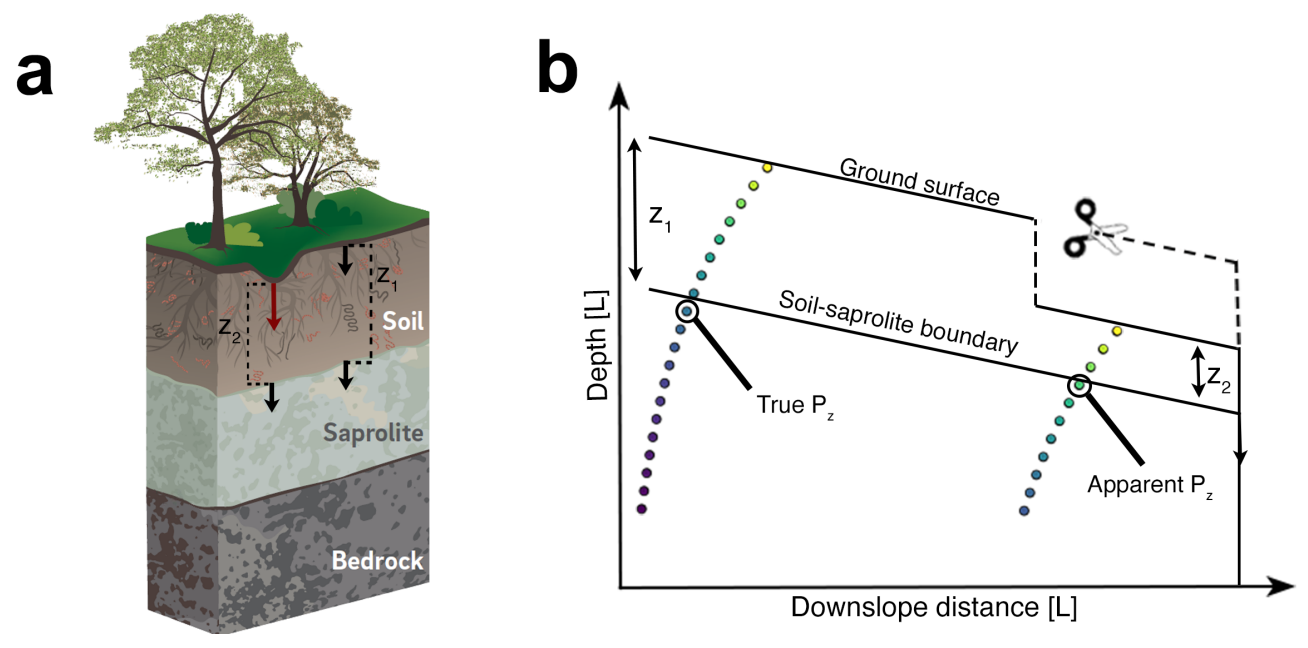

\section{Fig. 2 - Diagrammatic representation of how the observed depth parameter impacts ${ }^{10} \mathrm{Be}$ production rates at depth beneath the surface}

An idealized pedon in panel a shows the subaerial and soil-saprolite interfaces. Soil thickness at position $Z_{1}$ is in steady state, defined by equal rates of lowering at both interfaces. Soil thickness at position $Z_{2}$ is out of steady state, shown by the greater rate of lowering at the subaerial surface (red arrow). A 2D hillslope diagram in panel $\mathbf{b}$ shows the impact of changing the depth parameter $(z)$ on the ${ }^{10} \mathrm{Be}$ production rate. Higher apparent rate of ${ }^{10} \mathrm{Be}$ production suggest faster soil production rates. Decoupled lowering rates at the subaerial and soil-saprolite interfaces causes fast soil production rates to be associated with thin soil covering, and vice versa. between point-based ${ }^{10} \mathrm{Be}$-derived soil production rate $(\varepsilon)$ and soil depth $(z)$ measurements:

$$
\varepsilon(z)=a * e^{-(k z)}
$$

Where the coefficients $(a)$ and $(k)$ are fit to empirical data from the studied landscape. The magnitude of (a) reflects the maximum soil production rate and $(k)$ is the steepness of the regression line. In this study, we show how error in the measured soil production rate $(\varepsilon)$ introduced through the ${ }^{10} \mathrm{Be}$ production rate $\left(P_{z}\right)$ by the observed depth parameter $(z)$ affects the soil production function by tracking the changes in the exponent coefficient $(k)$ over a series of numerical simulations (see Methods). 
The model simulates field studies of soil production, in which a researcher selects several locations across a landscape to excavate soil, records the observed depth to saprolite, measures the $\left[{ }^{10} \mathrm{Be}\right]$ in a sample from the top of the saprolite, and derives a soil production function for the study area (equation 1). Each simulation begins with an array of values representing the thickness of soil mantling saprolite or bedrock, and an array of $\left[{ }^{10} \mathrm{Be}\right]$ concentration values that reflect soil production rate equal to surficial erosion. Changes in surficial erosion strip away a portion of the soil mantle, without immediately impacting the $\left[{ }^{10} \mathrm{Be}\right]$ at the base of the soil mantle or the soil production rate. The array of "stripped" soils and soil production rates are fit function that existed when the model was in steady state. In most cases, the new soil production function will have a spuriously steep exponent $(k)$.

New values of $(k)$ depend on the differences in thickness between the soils before the pulse of erosion. If the initial array contains soil pits of equal thickness, with equal soil production rates, removing different amounts of soil at each position produces a soil production function where the exponent is equal to the quotient of the soil bulk density $\left(\rho_{S}\right)$ and the attenuation length of ${ }^{10} \mathrm{Be}$ production in the subsurface $(\Lambda)$. This artifact arises regardless of the quantity or distribution of "stripped" soil. Soil bulk density, another soil property measured in the field, drives linear steepening of $(k)$. Reported bulk density values, ranging from $1.2-2.7 \mathrm{~g}$ $\mathrm{cm}^{-3}$, would correspond to artifactual exponent values between -0.008 and -0.016 respectively, if depth to saprolite was recorded incorrectly. This was noted in an early study, ${ }^{14}$ which suggested that exponent values steeper than $\frac{\rho_{g}}{\Lambda}$ for the site-measured soil density validate the exponential form of the relationship between soil depth and soil production rate. 

pulses may drive the exponent value beyond $\frac{\rho_{g}}{\Lambda}$, to encompass the full range reported in the literature (inset Fig. 1A). We tested the effect of an erosion pulse on simulated data modeled to represent two conditions: soil production rate exponentially dependent on soil depth and meancentered soil production rate independent of soil depth. Pre-erosion $\left[{ }^{10} \mathrm{Be}\right]$ concentrations were modeled for these two relationships, given the same initial array of soil depth values (Fig. S4). The results presented here show a simple scenario of soil stripping, applied to both the exponential and mean-centered frameworks. Soil stripping across the array ranges from $10 \%$ of the original soil depth, to a maximum percent loss value (Fig. 3A\&B). Soil production functions from the literature are plotted for comparison (Fig. 3C).
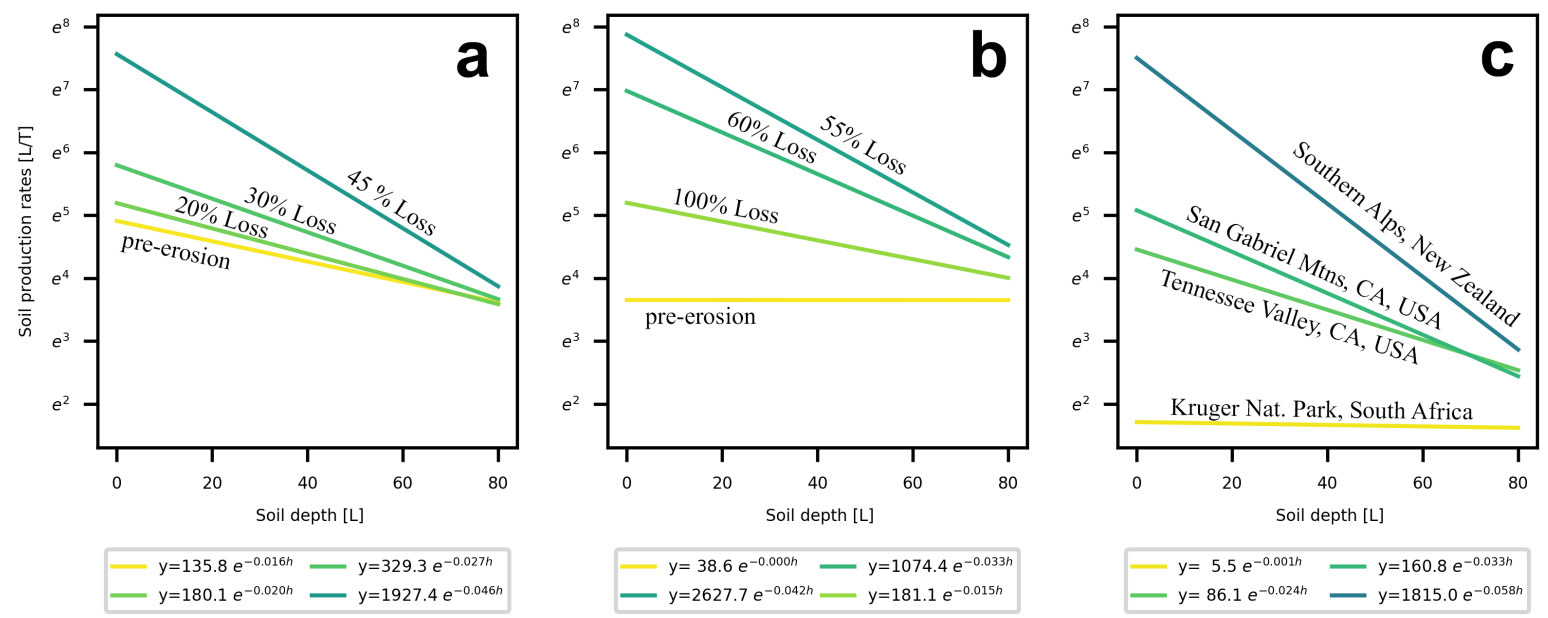

Fig. 3 - Apparent depth-dependent soil production arising due to pulses of surface erosion in two modeled scenarios, compared with soil production functions from the published literature.

$\mathbf{a}$ and $\mathbf{b}$ show soil production functions that arise due to pulses of erosion, with a greater apparent dependence on depth than exists at steady state (when soil production and surficial erosion are equal). The steady-state relationship is plotted in yellow for panels a and $\mathbf{b}$. Model scenarios shown here are those producing similar exponent values to soil production functions derived from empirical data, which are shown in panel c. 

(e.g. Fig. 3A) or independent of soil depth (e.g. Fig. 3B), thinning the soil mantle on a timescale shorter than is required to re-establish equilibrium in the cosmogenic radionuclide concentration can generate an apparently exponential relationship between soil production rate and soil depth. If, at steady state, this relationship is exponential, any amount of instantaneous erosion will steepen the exponent in a regression fit to the data. Even large compilations of soil production rates are likely to have a greater apparent dependence on soil depth, if some sites in the compilation experience unsteady surficial erosion. This is likely to occur in many places, and 
between soil erosion and production, the result is a stark caution that anthropogenically

accelerated erosion may not give rise to a concomitant, matched rise in soil production.

1. Verheijen, F. G. A., Jones, R. J. A., Rickson, R. J. \& Smith, C. J. Tolerable versus actual soil erosion rates in Europe. Earth-Science Rev. 94, 23-38 (2009).

2. Cease, A. J. et al. Heavy livestock grazing promotes locust outbreaks by lowering plant nitorgen content. Warn. - Sch. For. Nat. Resour. 335, 467-469 (2012).

3. Montgomery, D. R. Soil erosion and agricultural sustainability. Proc. Natl. Acad. Sci. U. S. A. 104, 13268-13272 (2007).

4. Dietrich, W. E., Hsu, M. \& Montgomery, D. R. A process based model for colluvial soil depth and shallow landsliding using digital elevation data. Hydrol. Process. 9, 383-400 (1995).

5. Heimsath, A. M., Dietrich, W. E., Nishiizumi, K. \& Finkel, R. C. The soil production function and landscape equilibrium. Nature 388, 358-361 (1997).

6. NRCS. NRCS Global Soil Regions map.

7. Dixon, J. L. \& Riebe, C. S. Tracing and pacing soil across slopes. Elements 10, 363-368 (2014).

8. Carson, M. A. \& Kirkby, M. J. Hilslope form and Process. (Cambridge University Press, 1972).

9. Mudd, S. M. \& Yoo, K. Reservoir theory for studying the geochemical evolution of soils. J. Geophys. Res. Earth Surf. 115, 1-13 (2010).

10. Heimsath, A. M., Chappell, J., Dietrich, W. E., Nishiizumi, K. \& Finkel, R. C. Soil production on a retreating escarpment in southeastern Australia. Geology 28, 787-790 (2000).

11. Heimsath, A. M., Chappell, J., Dietrich, W. E., Nishiizumi, K. \& Finkel, R. C. Late Quaternary erosion in southeastern Australia: A field example using cosmogenic nuclides. Quat. Int. 82, 169-185 (2001).

12. Heimsath, A. M., DiBiase, R. A. \& Whipple, K. X. Soil production limits and the transition to bedrock-dominated landscapes. Nat. Geosci. 5, 210-214 (2012).

13. Heimsath, A. M., Dietrich, W. E., Nishiizumi, K. \& Finkel, R. C. Stochastic processes of soil production and transport: Erosion rates, topographic variation and cosmogenic nuclides in the Oregon coast range. Earth Surf. Process. Landforms 26, 531-552 (2001).

14. Heimsath, A. M., Furbish, D. \& Dietrich, W. E. The illusion of diffusion: Field evidence for depth-dependent sediment transport. Geology 33, 949-952 (2005).

15. Larsen, I. J. et al. Rapid soil production and weathering in the Southern Alps, New Zealand. Science (80-. ). 343, 637-640 (2014).

16. Owen, J. et al. The sensitivity of hillslope bedrock erosion to precipitation. Earth Surf. Process. Landforms 36, 117-135 (2011).

17. Heimsath, A. M., Chadwick, O. A., Roering, J. J. \& Levick, S. R. Quantifying erosional equilibrium across a slowly eroding, soil mantled landscape. Earth Surf. Process. Landforms 45, 499-510 (2020).

18. Riggins, S. G., Anderson, R. S., Anderson, S. P. \& Tye, A. M. Solving a conundrum of a steady-state hilltop with variable soil depths and production rates, Bodmin Moor, UK. Geomorphology 128, 73-84 (2011).

19. Byun, J., Heimsath, A. M., Seong, Y. B. \& Lee, S. Y. Erosion of a high-altitude, low- 
relief area on the Korean Peninsula: Implications for its development processes and evolution. Earth Surf. Process. Landforms 40, 1730-1745 (2015).

20. Ferrier, K. L., Kirchner, J. W. \& Finkel, R. C. Weak influences of climate and mineral supply rates on chemical erosion rates: Measurements along two altitudinal transects in the Idaho Batholith. J. Geophys. Res. Earth Surf. 117, 1-21 (2012).

21. Dixon, J. L., Heimsath, A. M. \& Amundson, R. The critical role of climate and saprolite weathering in landscape evolution. Earth Surf. Process. Landforms 34, 1507-1521 (2009).

22. Wilkinson, M. T. et al. Soil production in heath and forest, Blue Mountains, Australia: Influence of lithology and palaeoclimate. Earth Surf. Process. Landforms 30, 923-934 (2005).

23. Jenny, H. Factors of soil formation: a system of quantitative pedology. (Courier Corporation, 1994).

24. Amundson, R., Heimsath, A. M., Owen, J., Yoo, K. \& Dietrich, W. E. Hillslope soils and vegetation. Geomorphology 234, 122-132 (2015).

25. Hurst, M. D., Mudd, S. M., Attal, M. \& Hilley, G. E. Hillslopes record the growth and decay of landscapes. Science (80-. ). 341, 868-872 (2013).

26. Roering, J. J., Kirchner, J. W. \& Dietrich, W. E. Evidence for nonlinear, diffusive sediment transport on hillslopes and implications for landscape morphology. Water Resour. Res. 35, 853-870 (1999).

27. Small, E. E., Anderson, R. S., Hancock, G. S. \& Harbor, J. Estimates of the rate of regolith production using 10Be and 26Al from an alpine hillslope. Geomorphology 27; 12, 131-150 (1999).

28. Crosby, B. T. \& Whipple, K. X. Knickpoint initiation and distribution within fluvial networks: 236 waterfalls in the Waipaoa River, North Island, New Zealand.

Geomorphology 82, 16-38 (2006).

29. Fernandes, F. \& Dietrich, E. Hillslope evolution by diffusive processes: The timescale for equilibrium adjustments. Water Resour. Res. 33, 1307-1318 (1997).

30. Heimsath, A. M. Eroding the land: Steady state and stochastic rates and processes through a cosmogenic lens. Geochim. Cosmochim. Acta 70, A241 (2006).

31. Mudd, S. M. \& Furbish, D. Responses of soil-mantled hillslopes to transient channel incision rates. J. Geophys. Res. Earth Surf. 112, 1-12 (2007).

32. Gosse, J. C. \& Phillips, F. M. Terrestrial in situ cosmogenic nuclides: Theory and application. Quat. Sci. Rev. 20, 1475-1560 (2001).

33. Dunai, T. J. Cosmogenic Nuclides: Principles, concepts and applications in the Earth surface sciences. (Cambridge University Press, 2010).

34. Lal, D. Cosmic ray labeling of erosion surfaces: in situ nuclide production rates and erosion models. Earth Planet. Sci. Lett. 104, 424-439 (1991).

35. Dixon, J. L. \& von Blanckenburg, F. Soils as pacemakers and limiters of global silicate weathering. Comptes Rendus - Geosci. 344, 597-609 (2012).

36. Riebe, C. S., Kirchner, J. W., Granger, D. E. \& Finkel, R. C. Strong tectonic and weak climatic control of long-term chemical weathering rates. Geology 29, 511-514 (2001).

37. Burke, B. C., Heimsath, A. M. \& White, A. F. Coupling chemical weathering with soil production across soil-mantled landscapes. Earth Surf. Process. Landforms 32, 853-873 (2007).

38. Ferrier, K. L., Kirchner, J. W. \& Finkel, R. C. Estimating millennial-scale rates of dust incorporation into eroding hillslope regolith using cosmogenic nuclides and immobile 
weathering tracers. J. Geophys. Res. Earth Surf. 116, 1-11 (2011).

39. Furbish, D. \& Fagherazzi, S. Stability of creeping soil and implications for hillslope evolution. Water Resour. Res. 37, 2607-2618 (2001).

40. Dietrich, W. E. et al. Geomorphic transport laws for predicting landscape form and dynamics. Geophys. Monogr. Ser. 135, 103-132 (2003).

41. Ferrier, K. L. \& Kirchner, J. W. Effects of physical erosion on chemical denudation rates: A numerical modeling study of soil-mantled hillslopes. Earth Planet. Sci. Lett. 272, 591599 (2008).

\section{Data availability:}

All data generated or analyzed during this study are included in this article and its supplementary information files.

\section{Code availability:}

Model code is available online at https://github.com/ejharril/repo/blob/master/Companion_GlobalSP.ipynb.

\section{METHODS}

\section{Global compilation of soil production studies}

We examined the total number of studies publishing soil production rates and co-spatial soil depth measurements ( $\mathrm{n}=18$, plus the new dataset from Puerto Rico published here). We first differentiated between datasets conforming to an exponential soil production function $(k \leq-0.01)$ from those that do not $(k>-0.01)$. Exponent values in most cases are included with the data in the original publications. For studies that do not quantify an exponential fit to their data, we ran a least squares regression on the published soil production rates and soil depths using the python library scipy.optimize ${ }^{42}$ function curve_fit. Curve_fit takes as an input the equation defining the form of the curve to be fit (equation 1 in the Main Text) which defines the number of free parameters that may be constrained by the regression. Curve_fit returns the best fit parameters $a$ and $k$ for the xy value arrays. The linear coefficient $a$ is sensitive to the externally imposed erosion rate, whereas the exponential coefficient $k$ depends on properties attenuating the energetic production of ${ }^{10} \mathrm{Be}$ (i.e. overburden thickness and soil bulk density). Extended Data Table 1 contains the site-information and soil production functions of studies previously 
published and complied in Fig. 1 from the main text of this manuscript. The location of these globally distributed studies is shown in Extended Data Fig. 1.

\section{Soil production rates measured in the Luquillo Mountains, Puerto Rico}

We calculated soil production rates for the Rio Blanco watershed in the Luquillo Mountains, Puerto Rico. The watershed is nearly entirely underlain by the Rio Blanco quartz diorite stock ${ }^{43}$. River profiles display pronounced steepened bedrock reaches until about halfway to their headwaters. An abrupt transition to low-gradient, gravel and sand bedded channels occurs at $\sim 600$ m elevation was identified as the front of a tectonically-triggered erosive wave traveling up the watershed via knickpoint propagation ${ }^{44,45}$. We sampled ridgelines upstream of this erosion front to avoid potential effects of topographic adjustment to the soil mantle thickness. Erosion in this watershed is dominated by landsliding ${ }^{46}$ and therefore we limited sampling to convex ridgetop sites. Typical soil profiles at this site have a thin $(<5 \mathrm{~cm}) \mathrm{O}$-horizon, a light-brown A-horizon, underlain in some cases by a gleyed Bt horizon, a thick clay-rich Bhorizon, and a reddish CB horizon that is chemically similar to the saprolite beneath this layer. Depth to saprolite ranges between $105-225 \mathrm{~cm}$ at these sites. Roots and worm tunnels can penetrate to the saprolite depth.

Samples were prepared in the Scripps Cosmogenic Isotope Laboratory, UC San Diego. We sieved soils into the $0.25-0.5 \mathrm{~mm}$ size fraction and purified them following an adaptation of the technique developed by Kohl and Nishiizumi (1992) until only etched quartz remained. We added a ${ }^{9}$ Be carrier (Supplier Purdue Rare Isotope Measurement Laboratory, Designation 2017.11.17-Be) to each sample prior to dissolution in hot, hydrofluoric acid. We separated Be from other elements following von Blanckenburg et al. (2004). We oxidized the samples over a flame to convert the $\mathrm{BeOH}$ to $\mathrm{BeO}$, added niobium powder to the $\mathrm{BeO}$ powder, then packed the 
351 samples into a cathode target. The ${ }^{10} \mathrm{Be} /{ }^{9} \mathrm{Be}$ ratio of the samples was measured by accelerator 352 mass spectrometry at PRIME Laboratory, Purdue University. Results were normalized to the $353 \quad 07 \mathrm{KNSTD}$ standard ${ }^{49}$ with a ${ }^{10} \mathrm{Be} /{ }^{9} \mathrm{Be}$ ratio of $2.79 \times 10^{-11} 50$. 354 Soil production rates were calculated from ${ }^{10} \mathrm{Be}$ concentrations using the CRONUS 355 online calculator ${ }^{51}$. We used a vegetation shielding parameter of $0.999^{52}$, a sample thickness of $35610 \mathrm{~cm}$, and ignoring additional shielding accounting for topography ${ }^{53}$. Quartz is resistant to 357 dissolution and becomes enriched in top layers of weathering profiles ${ }^{54}$. We quantified a quartz 358 enrichment factor for each soil profile by determining the quartz content of bulk soil samples 359 (unsieved) from the upper $10 \mathrm{~cm}$ of the weathering profile and the saprolite sample we used to 360 calculate soil production rates. We extracted the quartz by wet sieving with water to remove 361 clays $(<0.002 \mathrm{~mm}$ diameter) and gentle leaching with dilute $\mathrm{HCl}$ and aqua regia. For each of the 362 profiles we applied a quartz enrichment factor of 1.91 to the soil production rate calculation. 363 Bulk density values were measured by taking a sample in the field using plastic cubes of a 364 known volume, air drying, and weighing the sample.

\section{${ }^{10}$ Be derived soil production measurements}

Conventional methods for determining soil production rates in field studies were introduced by Heimsath et al. (1997) ${ }^{8}$ and detailed descriptions of chemical extraction methods ${ }^{47}$ and calculations are available in review papers ${ }^{32}$ and textbooks ${ }^{33}$. Simply put, a sample of Earth material is collected from below the base of the soil mantle, which is defined as the interface where material below retains the mineral fabric of the bedrock and the material above is disordered ${ }^{7}$. The accumulation of in situ ${ }^{10} \mathrm{Be}$ contained in the samples is extracted chemically, purified, and measured with Accelerator Mass Spectrometry. The concentration $\left(C_{z}\right)$ of ${ }^{10} \mathrm{Be}$ in 
atoms gram ${ }^{-1}$ at depth $(z)$ increases over time as a function of the ${ }^{10} \mathrm{Be}$ production rate at that $375 \operatorname{depth}\left(P_{z}\right)$ :

$$
C_{z}=P_{z} *\left(\frac{1}{\lambda+\frac{\rho E}{\Lambda}}\right)
$$

Soil production rates, or erosion rates, are calculated by convention using the online resource CRONUS ${ }^{51}$. CRONUS computes a surface ${ }^{10} \mathrm{Be}$ production rates from the sampling latitude, longitude and elevation and user-defined scaling factor that accounts for the topographic or vegetative shielding at the site. Authors report scaling factors, surface production rates, and ${ }^{10} \mathrm{Be}$ concentrations along with soil production rates for reproducibility. Depth-dependent ${ }^{10} \mathrm{Be}$ production rates are derived in two ways: by including a depth-shielding factor as an input to CRONUS or by attenuating the surface production rate determined by the software for the sampling location. The ${ }^{10} \mathrm{Be}$ production rate at depth $z(\mathrm{~cm})$ is related to the surface production rate $P_{0}$ by:

$$
P_{\mathrm{n}}=P_{0} e^{\frac{-n g}{x}}
$$

Soil production rate $(\varepsilon)$ is given by:

$$
\varepsilon=\frac{\Lambda}{\rho}\left(\frac{P_{z}}{c_{z}}\right)
$$

These are the three equations used in our model simulations and referenced in the model description below. Extended Data Table 3. defines the variables, measurement units, and the assigned constant values we use in the model simulations.

\section{Model description}

This model was written in Python 3.7. An annotated Jupyter notebook containing code to reproduce the model and figures in this manuscript is available online as part of the Supplementary Materials and in the corresponding author's GitHub repository. 

ranging from 100 to $180 \mathrm{~cm}$. We modeled an exponentially dependent scenario as:

$$
\varepsilon_{\exp }=200 * e^{(-0.02 z)}+n
$$

where $n$ is noise with a gaussian distribution and 1-sigma of 5 .

401

We modeled the mean-centered scenario as:

$$
\varepsilon_{\text {ran }}=40 \pm 5
$$

using a random number generator with a gaussian distribution to determine $\varepsilon_{\text {ran }}$.

The concentration of ${ }^{10} \mathrm{Be}$ for every $z$ was calculated from equation 2 and the parameter values listed in Extended Data Table 6, using the values of $\varepsilon_{\text {ran }}$ and $\varepsilon_{\exp }$ as the surface erosion rate value. The steady state soil production rate, calculated from equation 4 , is identical to the surface erosion rate. The modeled values and the best fit exponential regression for both the exponential and mean-centered scenarios in steady-state are shown in Extended Data Fig.3. The regression line is fit with equation 1 from the main text.

$$
\varepsilon(z)=a * e^{-(k z)}
$$

And the values of $k$ for these two steady state soil production functions are reported in Extended Data Fig.S3.

Each value in the soil thickness array is then reduced by a unique length $\left(L_{1}, L_{2}, \ldots L_{10}\right)$ to produce an observed depth $\left(z^{\prime}{ }_{1}, z^{\prime}{ }_{2} \ldots z^{\prime}{ }_{10}\right)$ following soil-stripping erosion. Values in the length array, that determine the depth of soil stripping applied, are calculated as a percentage of the uneroded soil depth value $(z)$. For the results presented in the main text of this manuscript, we modeled these arrays as increasing linearly from $20 \%$ loss to a maximum loss value. We report maximum loss values ranging from $10 \%$ to $100 \%$ (Extended Data Fig. 4). Both the depth-array and the percentage-loss array are ordered from least to greatest, thus, in each of the simulations 
we present here, initially thin soils are eroded by a smaller percentage than initially thick ones. In mountainous regions, the ridge crest is the most geomorphically stable position, and supports the thinnest soil mantle. Slope-dependent flux thickens soils as hillslope gradients increase, but sediment transport also becomes increasingly unstable ${ }^{26}$. As this model is intended to explore intra-site variability, more significant losses from thicker soil profiles is justifiable.

The true soil production rate - i.e. the concentration of ${ }^{10} \mathrm{Be}$ nuclides at the base of the soil mantle - is held constant. ${ }^{10} \mathrm{Be}$ concentrations represent time-integrated denudation rates, which may be significantly different from the instantaneous rate $e^{55}$ even without the additive error of uncertainty in the soil thickness over the timescale of ${ }^{10} \mathrm{Be}$ accumulation. Existing work has demonstrated that the time it takes the radionuclide concentration to equilibrate to the instantaneous rate declines as denudation rate increases ${ }^{34}$, and increases with the amplitude and frequency of change $\mathrm{e}^{30,56}$. For this study, we did not reproduce work demonstrating that error is introduced by the lag time to isotopic equilibrium.

We calculated apparent soil production rates $\left(\varepsilon_{1}, \varepsilon_{2}, \ldots \varepsilon_{10}\right)$ from the ${ }^{10} \mathrm{Be}$ concentration and the ${ }^{10} \mathrm{Be}$ production rate implied by the observed depth to saprolite. We applied the exponential regression to the new data for each of the eroded soil arrays and track changes in the exponential coefficient $(k)$ of the best-fit equation (Extended Data Fig. 5). A subset of those results is presented and discussed in the main text of the manuscript.

\section{Global compilation of "controlling variables" in soil production processes}

We conducted an extensive literature review to compile site-specific value estimates for factors moderating either soil depth or soil production rate. For each study site, we identified as many of the following factors as possible: precipitation rate, average annual temperature and temperature extremes, vegetation type and percent cover, vegetation decomposition rates, 
bedrock lithologies, water table depth, chemical depletion of soil and saprolite relative to the bedrock, and the average annual volume of dust deposition. These factors for each site and the references from which we obtain them are compiled in Extended Data Table 2. We used no statistical methods comparing the site factors, however, none of the variables explain the split between the two populations. Granite and granodiorite make up a larger representative fraction of the bedrocks in the equilibrium (nonconforming) group. Granites may retain relict topographies for longer durations than other bedrocks types, as has been observed for adjacent quartz diorite and volcanoclastic watersheds in the Luquillo Mountains, Puerto Rico ${ }^{44,45}$. In the global data, wetter climates correlate with increasing soil production overall ${ }^{24}$ but depth dependence has no relationship to site aridity.

Other trends in the data, for example the mean or maximum soil production rate, vary systematically with climatic and geologic variables as has been described by other authors ${ }^{24}$. Extended Data Fig. 6 shows the absolute value of soil production function exponents plotted vs the aridity index, calculated following Amundson et al. ${ }^{24}$ as the mean annual precipitation (mm $\left.\mathrm{yr}^{-1}\right)$ divided by the mean annual temperature $\left({ }^{\circ} \mathrm{K}\right)$.

The effects of time on soil production rates have previously been considered in terms of the site seismicity ${ }^{57}$, a proxy for uplift. Rates of chemical erosion increase with higher rates of physical erosion globally ${ }^{35,36,58,59}$, but the front of chemical erosion is often located deeper than the mobilization front ${ }^{60}$ that defines the base of the soil layer ${ }^{7}$. In our compilation, we find the degree of weathering in soils and the depth of saprolite is not a control on whether a site conforms to an exponential soil production function (Supplemental Table 1). Deeply weathered sites, such as those in the escarpment regions of Australia, and locations where fresh bedrock is near the surface, such as the southern Alps in New Zealand and the San Gabriel Mountains in 
California, all have robust exponential soil production functions. Similarly, the deeply weathered Luquillo Mountains and South African sites as well as the transport-limited Wind River Range and Salmon Mountains, have no clear relationship between soil depth and soil production. We consider the influence of water table position on soil production, because groundwater may slow chemical weathering and pore pressure gradients may induce grain spallation. However, the cursory compilation of site hydrology characteristics in Supplemental Table 2 does not indicate that the presence of a water table near the surface, or a dominance of overland flow vs vadose zone processes can be invoked to explain the divisions between the two populations of study areas.

We consider whether the addition of plant organic material could inflate the soil volume, obscuring the presence of depth-dependent soil production in some sites. For this analysis, we approximate litter incorporation from litterfall and decomposition rates. Unique data is not available for all the sites; therefore, we infer litter volume and decomposition time from the climate zone and dominant ecosystem life form. We identified the climate zone of each study area following the Köppen-Geiger classification system ${ }^{61}$. From the descriptions of the vegetation at each site, we classified the dominant life form of the ecosystem (i.e. needleleaf or broadleaf, evergreen or deciduous). Based on these classifications, we use approximate litterfall rates $^{62}$ and residence times from global compilations to estimate annual soil amendments from plant material. We add approximate volumes of annual dust deposition ${ }^{63}$ although without considering the degree to which this process is offset by dissolution or leaching. The precipitation of secondary minerals, coatings, and calcium-carbonate could likewise contribute small volumes of material to soil profiles and/or retain soil volume that would otherwise be lost during weathering. Additive processes are offset by processes acting to decrease the soil mantle 
thickness, such as compaction by shear or burrowing animals, or downslope translocation of clays. Although far from an exhaustive review, we present qualitative rankings for soil additive and subtractive processes here:

Deposition of organic matter - decomposition a function of litter quality

$(+) \mathrm{PR} \rightarrow \mathrm{NZ} \rightarrow \mathrm{AU} \rightarrow \mathrm{OR} \rightarrow \mathrm{CA}$ costal $\rightarrow \mathrm{CA}$ alpine $\rightarrow$ inland mountain $\rightarrow$ Chile, SA (-) Deposition of dust (offset to a degree by leaching/dissolution)

$(+)$ inland Mountain $\rightarrow$ Chile $\rightarrow$ PR $\rightarrow$ CA alpine $\rightarrow$ CA coastal $\rightarrow$ OR $\rightarrow$ AU $\rightarrow$ NZ, SA (-) Precipitation of secondary minerals and oxide coatings - calcium-carbonate, clays

$(+) \mathrm{PR} \rightarrow$ Chile $\rightarrow \mathrm{PR} \rightarrow \mathrm{AU}, \mathrm{SA} \rightarrow \mathrm{OR}, \mathrm{CA}$ costal $\rightarrow \mathrm{CA}$ alpine $\rightarrow$ NZ, inland mountain $(-)$ Compaction by shear or burrowing $(-)$ OR, CA costal, AU, PR $\rightarrow$ AU, SA $\rightarrow$ CA alpine, inland mountain, $\mathrm{NZ} \rightarrow$ Chile $(+)$

\section{Identification of topographic parameters and geomorphic change indices}

We find convincing evidence exists in the descriptions of topographic context and geomorphic processes at each site to classify the groups as transient or in geomorphic equilibrium based on the likelihood that hillslope lowering is occurring at a similar rate across space. To categorize the topographic setting at each site we use the primary author's site descriptions and photographs. Site descriptions identifying ridgelines as parabolic (constant curvature) we consider more likely to lower at a spatially constant rate, whereas convex, nonlinear ridgelines we consider more likely to lower at spatially variant rates. When available, we examined high resolution digital elevation models for the study areas and identified the point locations of the soil production samples. This allowed us to identify studies where field sampling targeted low-relief or hilly sections of the topography perched within a landscape that was 
elsewhere deeply incised and steeply convex. Such sections in a landscape have been described as "relict" topographies ${ }^{64}$, or locations in which hillslope gradients grade to an elevation higher than the local base level. Often, relict topographic sections are insulated from base-level lowering and relief driving processes acting on the broader landscape ${ }^{28}$. Similarly, it is widely hypothesized that high-relief plateaus are formed when a section of land is smoothed by geomorphic processes then subsequently uplifted and remains disconnected from the base level compiled in Supplemental Table 3.

We also compared catchment-average denudation rates to point measurements of erosion on hillslopes. If the catchment average rates span the measured range of soil production rates, we following uplift ${ }^{65}$. We consider sites that appear to be disconnected from a locally lowering base level as more likely to be lowering at a spatially constant rate. Primary site descriptions are

We also compared catchment-average denudation rates to point measurements of erosion on hillslopes. If the catchment average rates span the measured range of soil production rates, we consider it evidence for spatially uniform surface lowering. If the catchment average denudation is higher than the soil production rates for a landscape, we consider it evidence for spatially variable surface lowering. Published values for catchment denudation are included in Supplemental Table 3. For many of the studied locations, only one or few catchment averaged denudation rates are reported, or we were not able to identify which catchment contained the reported soil production sample.

\section{Methods references}

42. Virtanen, P. et al. SciPy 1.0-Fundamental Algorithms for Scientific Computing in Python. (2019).

43. Seiders, V. M. Geologic map of the El Yunque quadrangle, Puerto Rico. 658, (1971).

44. Brocard, G. Y., Willenbring, J. K., Miller, T. E. \& Scatena, F. N. Relict landscape resistance to dissection by upstream migrating knickpoints. J. Geophys. Res. Earth Surf. 121, 1182-1203 (2016).

45. Brocard, G. Y., Willenbring, J. K., Scatena, F. N. \& Johnson, A. H. Effects of a tectonically-triggered wave of incision on riverine exports and soil mineralogy in the Luquillo Mountains of Puerto Rico. Appl. Geochemistry 63, 586-598 (2015).

46. Brown, E. T., Stallard, R. F., Larsen, M. C., Raisbeck, G. M. \& Yiou, F. Denudation rates 
determined from the accumulation of in situ-produced $10 \mathrm{Be}$ in the luquillo experimental forest, Puerto Rico. Earth Planet. Sci. Lett. 129, 193-202 (1995).

47. Kohl, C. P. \& Nishiizumi, K. Chemical isolation of quartz for measurement of in-situ produced cosmogenic nuclides. Geochim. Cosmochim. Acta 56, 3583-3587 (1992).

48. von Blanckenburg, F. Cosmogenic nuclide evidence for low weathering and denudation in the wet, tropical highlands of Sri Lanka. J. Geophys. Res. 109, (2004).

49. Nishiizumi, K. et al. Absolute calibration of 10 Be AMS standards. Nucl. Instruments Methods Phys. Res. Sect. B Beam Interact. with Mater. Atoms 258, 403-413 (2007).

50. Balco, G. et al. Regional beryllium-10 production rate calibration for late-glacial northeastern North America. Quat. Geochronol. 4, 93-107 (2009).

51. Balco, G., Stone, J. O., Lifton, N. A. \& Dunai, T. J. A complete and easily accessible means of calculating surface exposure ages or erosion rates from $10 \mathrm{Be}$ and $26 \mathrm{Al}$ measurements. Quat. Geochronol. 3, 174-195 (2008).

52. Plug, L. J., Gosse, J. C., McIntosh, J. J. \& Bigley, R. Attenuation of cosmic ray flux temperate forest. J. Geophys. Res. Earth Surf. 112, (2007).

53. DiBiase, R. A. Short communication: Increasing vertical attenuation length of cosmogenic nuclide production on steep slopes negates topographic shielding corrections for catchment erosion rates. Earth Surf. Dyn. 6, 923-931 (2018).

54. Riebe, C. S., Kirchner, J. W. \& Granger, D. E. Quantifying quart enrichment and its consequences for cosmogenic measurements of erosion rates from alluvial sediment and regolith. Geomorphology 40, 15-19 (2001).

55. Heimsath, A. M. Eroding the land: Steady-state and stochastic rates and processes through a cosmogenic lens. Spec. Pap. Geol. Soc. Am. 415, 111-129 (2006).

56. Mudd, S. M. Detection of transience in eroding landscapes. Earth Surf. Process. Landforms 42, 24-41 (2017).

57. Suresh, P. O., Dosseto, A., Hesse, P. \& Handley, H. K. Soil formation rates determined from Uranium-series isotope disequilibria in soil profiles from the southeastern Australian highlands. Earth Planet. Sci. Lett. 379, 26-37 (2013).

58. Gaillardet, J., Dupré, B., Allègre, C. J. \& Négrel, P. Chemical and physical denudation in the Amazon River Basin. Chem. Geol. 142, 141-173 (1997).

59. West, A. J., Galy, A. \& Bickle, M. Tectonic and climatic controls on silicate weathering. Earth Planet. Sci. Lett. 235, 211-228 (2005).

60. Dixon, J. L., Heimsath, A. M., Kaste, J. \& Amundson, R. Climate-driven processes of hillslope weathering. Geology 37, 975-978 (2009).

61. Kottek, M., Grieser, J., Beck, C., Rudolf, B. \& Rubel, F. World map of the KöppenGeiger climate classification updated. Meteorol. Zeitschrift 15, 259-263 (2006).

62. Bray, J. R. \& Gorham, E. Litter Production in Forests of the World. Adv. Ecol. Res. 2, 101-157 (1964).

63. Jickells, T. D. et al. Global iron connections between desert dust, ocean biogeochemistry, and climate. Science (80-. ). 308, 67-71 (2005).

64. Whipple, K. X., DiBiase, R. A. \& Crosby, B. T. Bedrock Rivers. in Treatise on geomorphology 550-573 (Elsevier, 2013). doi:10.1016/B978-0-12-374739-6.00254-2

65. Clark, M. K. et al. Late Cenozoic uplift of southeastern Tibet. Geology 33, 525-528 (2005).

\section{Acknowledgments:}

We thank N. Gasparini, L. Sklar, and D. Granger for feedback. This research was supported by NSF grants 1848637 and 1331841 awarded to Dr. Jane K. Willenbring. 


\section{Author contributions}

E.J.H: Conceptualization, Methodology, Investigation, Formal analysis, Visualization, Writing Original draft. J.K.W: Conceptualization, Supervision, Writing -Review \& Editing. G.B: Methodology, Investigation, Writing - Review \& Editing. Supplemental Information is available for this paper.

Correspondence and requests for materials should be addressed to ejharri1@stanford.edu.

\section{Ethics declarations}

The authors declare no competing interests.

\section{Extended data figures and tables}

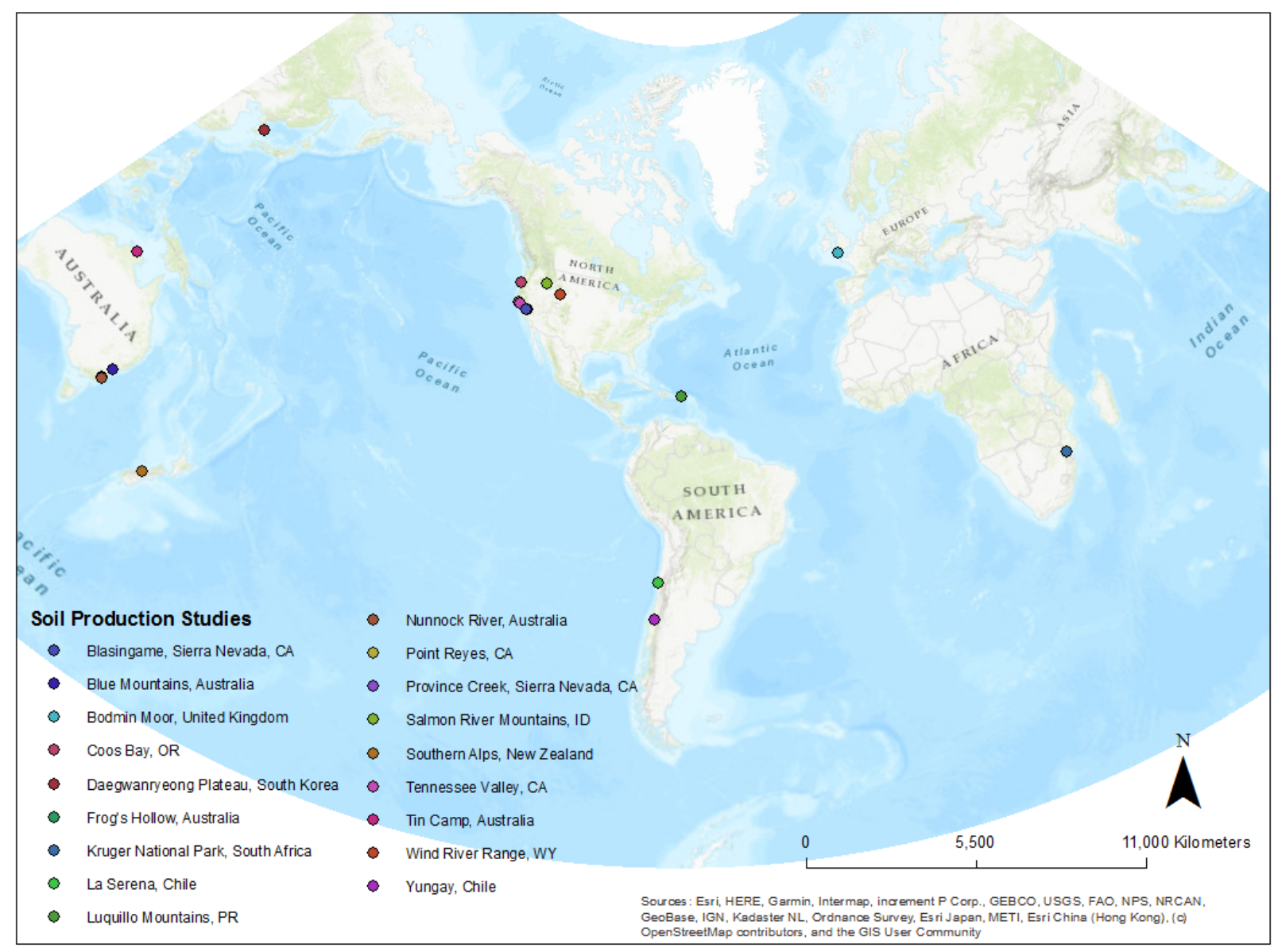

Extended Data Fig. 1. Global map of soil production studies. Approximate locations of the currently published soil production studies known to these authors. 
606

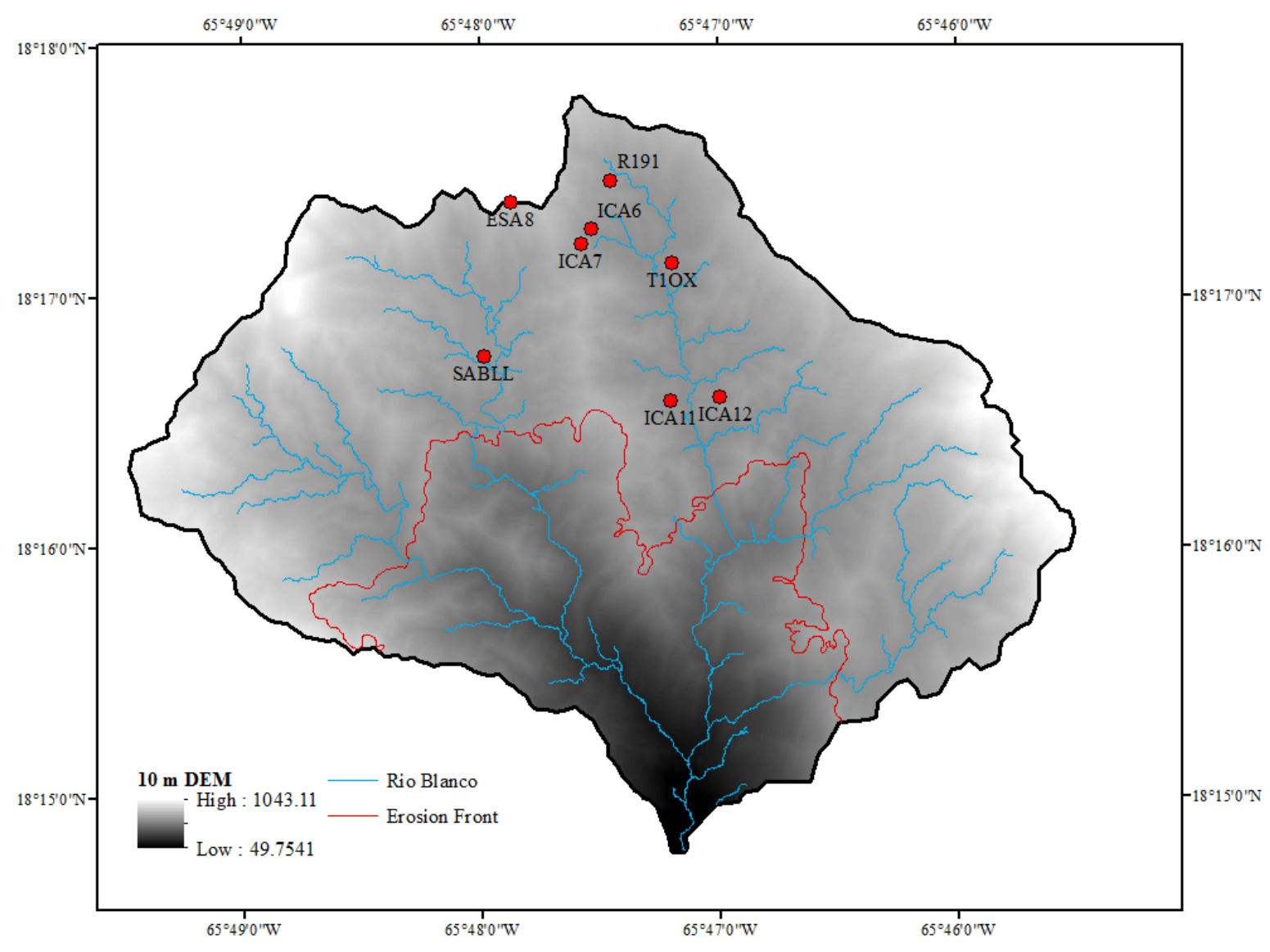



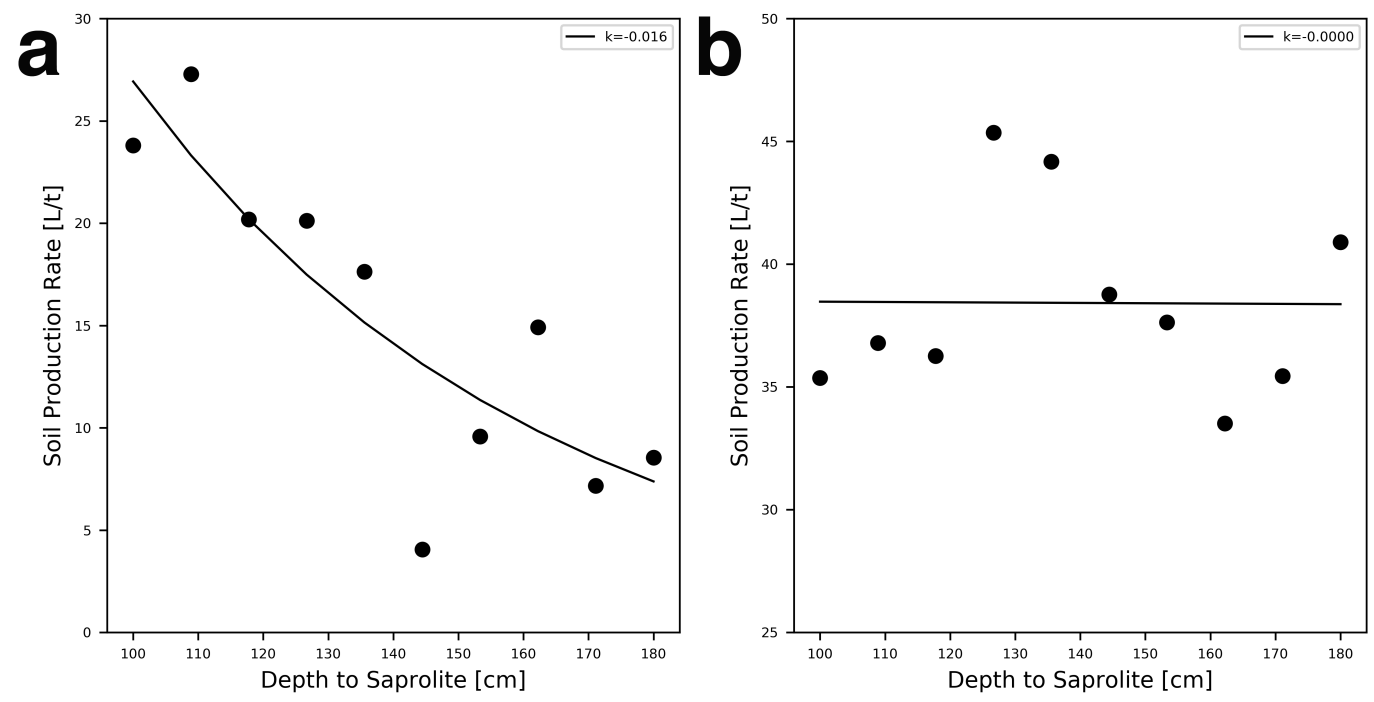

610

Extended Data Fig. 3. Steady state values and exponential regressions for the a, exponential and b, mean-centered simulations. 


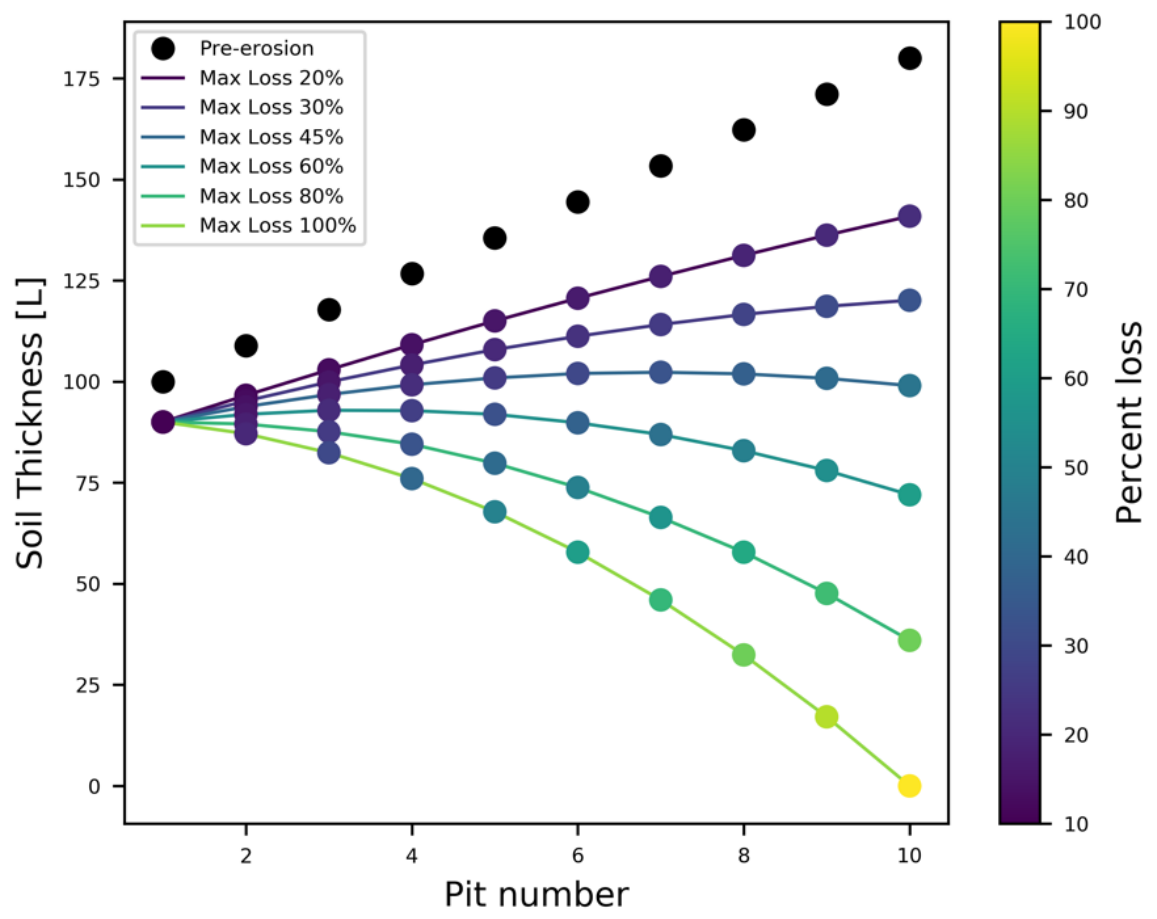

615 Extended Data Fig. 4. Erosion scenarios ranging from $10 \%$ to a max loss of $20 \%$, up to a $\max$ 616 617 loss of $100 \%$ from the initial array of depth values. 

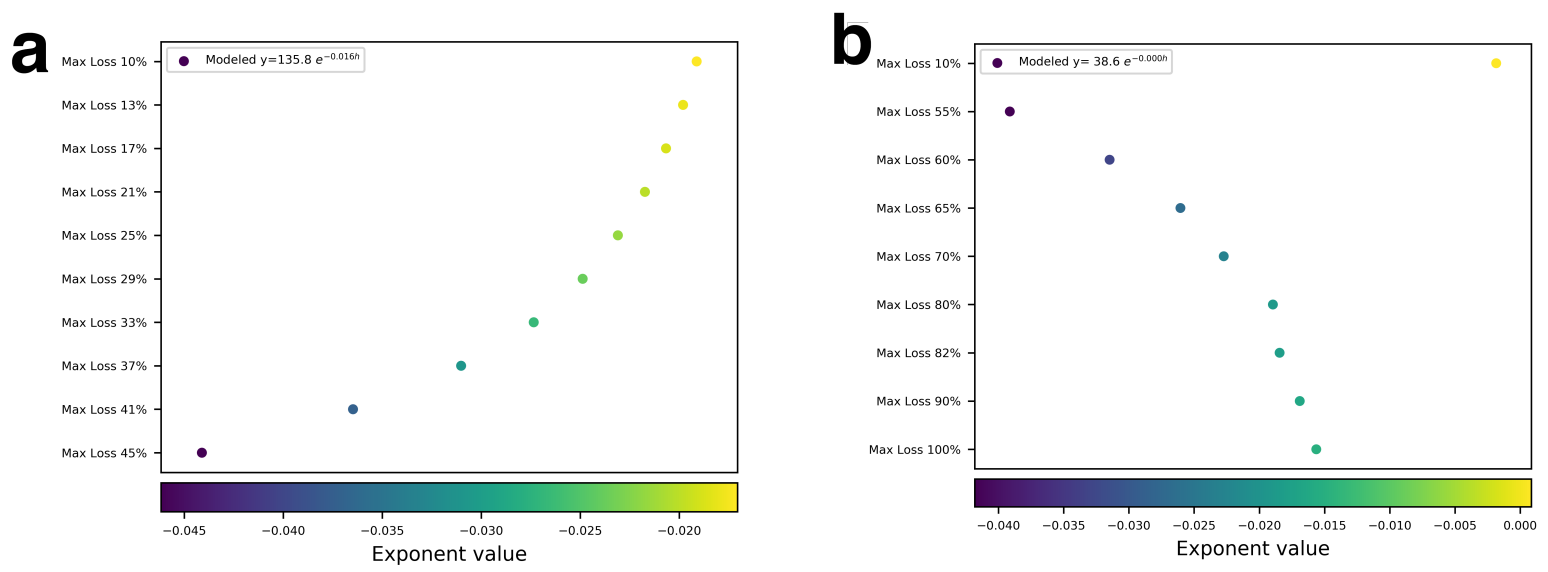

Extended Data Fig. 5. Exponent values for soil stripping erosion scenarios. a begins with an exponential soil production function. b begins with a mean-centered, depth independent, soil production scenario. Note the differences in the y-scale. 

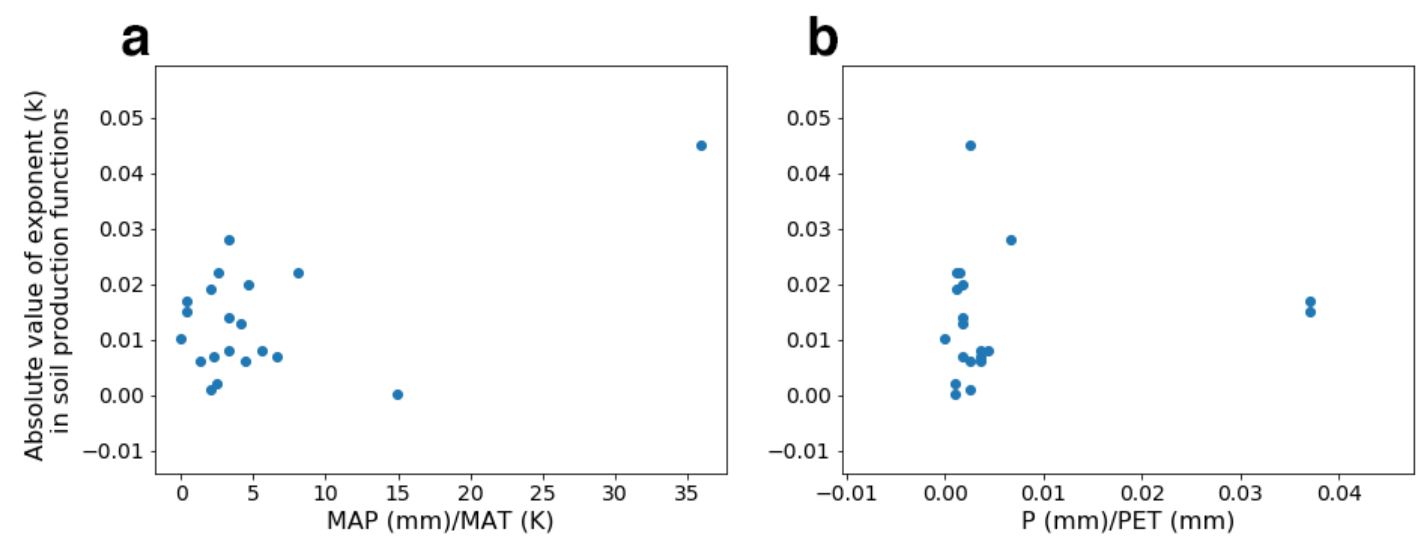

Extended Data Fig. 6. Climate vs. depth-dependence in soil production rates. a, the absolute value of the exponent in the best fit soil production function ( $k$ in Table $\mathrm{S} 1)$ is plotted vs. the mean annual precipitation $(\mathrm{mm})$ over the mean annual temperature $(\mathrm{K})$ (values listed in Table S1) following the aridity index measure in Amundson et al. (24). b, the absolute value of the exponent in the best fit soil production function ( $k$ in Table S1) is plotted vs. the mean annual precipitation $(\mathrm{mm})$ over the aridity index, calculated as the product of the mean annual precipitation and the mean annual evapotranspiration (values listed in Table S4). 
636

637

638

639

640

641

642

643

644

645

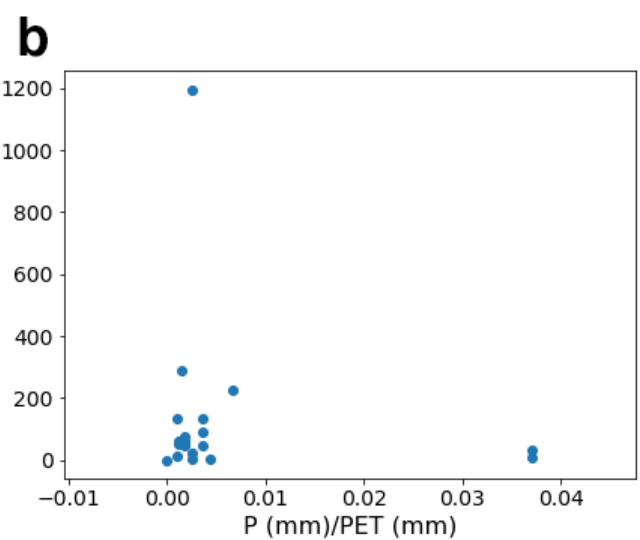

Extended Data Fig. 7. Climate vs. maximum soil production rates. a, the value of the coefficient in the best fit soil production function ( $a$ in Table S1) is plotted vs. the mean annual precipitation $(\mathrm{mm})$ over the mean annual temperature $(\mathrm{K})$ (values listed in Table S1) following the aridity index measure in Amundson et al. (24). b, the absolute value of the exponent in the best fit soil production function ( $a$ in Table S1) is plotted vs. the mean annual precipitation (mm) over the aridity index, calculated as the product of the mean annual precipitation and the mean annual evapotranspiration (values listed in Table S4). 
646

647

648

649

Extended Data Table 1. Site characteristics and soil production function parameters from published studies

\begin{tabular}{lrrrrl}
\hline \multicolumn{1}{c}{ Location } & $\mathbf{a}^{*}$ & \multicolumn{1}{c}{$\mathbf{k}^{*}$} & MAP $(\mathbf{m m})$ & MAT (C) & \multicolumn{1}{c}{ Lithology } \\
\hline Sites in Fig. 1B & & & & & \\
Puerto Rico & 134 & -0.0002 & 4500 & 27 & quartz diorite \\
South Korea & 60 & -0.007 & 1850 & 5 & granite \\
Bodmin Moor, UK & 22 & -0.006 & 1250 & 10 & granite \\
Sierra Nevadas, Providence Creek & 90 & -0.008 & 920 & 8.9 & granodiorite \\
Blue Mtns, Australia & 13 & -0.002 & 700 & 16.5 & sandstone \\
Salmon Mtns, Idaho & 133 & 0.007 & 660 & 14 & granite/granodiorite \\
Wind River Range, WY & 6 & 0.008 & 1500 & -3 & granite/granodiorite \\
Kruger Park, South Africa & 6 & -0.001 & 600 & 22 & granite \\
Sierra Nevadas, Blasingame & 47 & -0.006 & 370 & 16.6 & tonalite \\
Atacama, semiarid, stable & 7 & -0.015 & 100 & 13.6 & plutonic, mixed lithologies \\
Atacama, hyperarid & 1 & 0.0102 & 2 & 16 & plutonic, mixed lithologies \\
\hline Sites in Fig. 1A & & & & & \\
New Zealand & 1196 & -0.045 & 10000 & 5 & schist \\
Oregon Coast & 289 & -0.022 & 2300 & 11 & sandstone/siltstone \\
Tin Camp Australia & 46 & -0.020 & 1400 & 27 & sandstone \\
Tennessee Valley, California & 56 & -0.013 & 1200 & 14 & greywacke/greenstone \\
San Gabriels, CA & 225 & -0.028 & 950 & 13 & granite/metamorphic mixed \\
Point Reyes, CA & 76 & -0.014 & 940 & 15.5 & granodiorite \\
Nunnock River Australia & 62 & -0.022 & 720 & 11.4 & granite/granodiorite \\
Frog Hollow, Australia & 51 & -0.019 & 600 & 16 & granodiorite \\
Atacama, semiarid, active & 35 & -0.017 & 100 & 13.6 & plutonic, mixed lithologies \\
\hline * & & & & &
\end{tabular}


654 655 656

Extended Data Table 2. Soil production rate calculations for the Luquillo Mountains, Puerto Rico

\begin{tabular}{|c|c|c|c|c|c|c|c|c|c|c|}
\hline Site ID & Lat & Long & $\begin{array}{c}\text { Elev } \\
\text { m }\end{array}$ & $\begin{array}{c}\text { Density } \\
\mathrm{g} \mathrm{cm}^{-3}\end{array}$ & $\begin{array}{c}\text { Soil } \\
\text { depth } \\
\text { cm }\end{array}$ & $\begin{array}{l}\text { Depth } \\
\text { shield. }\end{array}$ & $\begin{array}{c}{\left[{ }^{10} \mathrm{Be}\right]} \\
\text { atoms g-1 }\end{array}$ & $\begin{array}{c}\text { AMS } \\
\text { Uncert. } \\
\text { atoms } \mathbf{g}^{-1} \\
\%\end{array}$ & $\begin{array}{c}\text { Erosion } \\
\text { rate } \mathbf{m m} \\
\mathbf{k y}^{-1}\end{array}$ & $\begin{array}{c}\text { Rate } \\
\text { Uncert. } \\
\text { mm ky }{ }^{-1}\end{array}$ \\
\hline R191 & 18.2911 & -65.7909 & 688 & 1.22 & 155 & 0.403 & 51700 & $\begin{array}{l}2790 \\
5.4 \%\end{array}$ & 152 & 6 \\
\hline ES A8 & 18.2896 & -65.7985 & 766 & 1.47 & 110 & 0.513 & 57200 & $\begin{array}{l}1090 \\
1.9 \%\end{array}$ & 142 & 4 \\
\hline IC A6 & 18.2879 & -65.7978 & 663 & 1.04 & 115 & 0.498 & 39300 & $\begin{array}{c}903 \\
2.3 \%\end{array}$ & 277 & 9 \\
\hline IC A7 & 18.2868 & -65.7930 & 684 & 1.15 & 135 & 0.455 & 82100 & $\begin{array}{l}1560 \\
1.9 \%\end{array}$ & 124 & 5 \\
\hline $\begin{array}{c}\text { IC A7 } \\
\text { rep }\end{array}$ & 18.2868 & -65.7930 & 684 & 1.15 & 135 & 0.455 & 71100 & $\begin{array}{c}3550 \\
5 \%\end{array}$ & 106 & 3 \\
\hline IC A11 & 18.2764 & -65.7867 & 630 & 1.78 & 105 & 0.545 & 68300 & $\begin{array}{l}2120 \\
3.1 \%\end{array}$ & 91 & 3 \\
\hline IC A12 & 18.2766 & -65.7833 & 656 & 1.62 & 130 & 0.455 & 28100 & $\begin{array}{l}1070 \\
3.8 \%\end{array}$ & 239 & 8 \\
\hline T1OX & 18.2856 & -65.7866 & 650 & 1.6 & 135 & 0.455 & 81700 & $\begin{array}{l}1550 \\
1.9 \%\end{array}$ & 74 & 2 \\
\hline SA LL & 18.2794 & -65.7997 & 661 & 1.6 & 225 & 0.264 & 56600 & $\begin{array}{l}1080 \\
1.9 \%\end{array}$ & 80 & 3 \\
\hline
\end{tabular}


660 Extended Data Table 3. Variable descriptions and model input values

\begin{tabular}{|c|c|c|c|}
\hline Variable & Variable description & Variable units & Model constants \\
\hline$C_{z}$ & ${ }^{10} \mathrm{Be}$ concentration at depth & [atoms gram $\left.{ }^{-1}\right]$ & Calculated \\
\hline$P_{0}$ & ${ }^{10} \mathrm{Be}$ production rate at the surface & [atoms gram $^{-1}$ year $^{-1}$ ] & 5.0 \\
\hline$P_{z}$ & ${ }^{10} \mathrm{Be}$ production rate at depth & [atoms gram $^{-1}$ year $^{-1}$ ] & Calculated \\
\hline$z$ & Depth below the surface & {$[\mathrm{cm}]$} & Calculated \\
\hline$\rho$ & Bulk density & [grams cm $\mathrm{cm}^{-3}$ ] & 1.4 \\
\hline$\lambda$ & ${ }^{10} \mathrm{Be}$ decay constant $\left(\ln 2 / \mathrm{t}_{1 / 2}\right)$ & [atoms year ${ }^{-1}$ ] & 0 \\
\hline$\epsilon$ & Surface erosion rate & {$\left[\mathrm{L} \mathrm{t}^{-1}\right]$} & Calculated \\
\hline$\Lambda$ & Mean attenuation length & {$\left[\mathrm{cm}^{-2}\right]$} & 165 \\
\hline
\end{tabular}

661 Variable descriptions and model input values for deriving soil production rates from ${ }^{10}$ Be production rates 662 and concentration measurements. 